\title{
Individual rights advocacy in tobacco control policies: an assessment and recommendation
}

\section{J E Katz}

Tobacco Control 2005;14(Suppl II):ii31-ii37. doi: 10.1136/tc.2004.008060

Efforts to control environmental tobacco smoke (ETS) could be assisted if the tobacco control movement gave greater emphasis to the issue of individual rights. Benefits that may accrue from the promotion of a clear individual rights perspective in tobacco control include adding coherence to the tobacco control advocacy agenda and winning support from those who may have been concerned about loss of personal freedom, excessive governmental power, use of social coercion, or the rights of smokers. Risks also attend to such a policy. It might inadvertently assist the tobacco industry, stir resistance to ETS limitation efforts, or confuse tobacco control supporters. On balance, though, liabilities are outweighed by the ethical and operational merits in tobacco control of a heightened pro-individual rights stance.

Correspondence to: Dr James E Katz, Rutgers University, 4 Huntington Street, New Brunswick, NJ 08901, USA; jimkatz@ scils.rutgers.edu
$\mathrm{T}$ he public health establishment is deeply concerned with rights, and emphasises as a core principle the freedom from harm. But conflicts can arise over rights, such as when the public health perspective encounters the individual freedom perspective. This perspective makes paramount individual freedom of action. When trying to claim a moral and ethical basis for public health policy, and tobacco control, some conflicts can arise over rights. For instance, there are many value choices involved in trade-offs among various kinds of rights, such as property rights (for example, commercial production and marketing of tobacco), individual liberty rights product), and the right to be let alone (for example, non-smokers to be free of tobacco pollution). Consequently there can be confusion and uncertainty over how to apply rights concepts to public policy and individual practice. Despite this confusion, individual rights rhetoric seems increasingly prominent in public pronouncements of control advocates. ${ }^{1}$ Indeed, some recent progress in reducing environmental tobacco smoke (ETS) could be attributable to the use of the individual rights argument. Still greater progress could be made in tobacco control if additional policy and rhetorical emphasis were given to individual rights, but doing so also entails some risk. The purpose of this article is to explore the problem space of individual rights in tobacco control and examine the advantages and disadvantages of using rights arguments to foster greater controls on ETS. (for example, freedom to consume a dangerous
INDIVIDUAL RIGHTS: SOME DEFINITIONS Types and importance of individual rights: public health and other perspectives

Individual rights are actions that society judges to be moral entitlements of each of its members. These entitlements revolve around life, liberty, and use of property. A public health perspective generally looks at these rights in descending order of priority, namely that rights to life trump those of liberty, which trump use of property. Yet other legitimate perspectives assign a different priority. Statements that reflect these alternative views include "Give my liberty or give me death" (Patrick Henry), or "I'll defend to the death your right to speak" (paraphrasing Voltaire). These are but a few indications of different hierarchies of precedence that particular individual rights should have. While agreeing that other perspectives and the rights priority they endorse are important and widely held, the perspective here largely assigns precedence to the public health viewpoint. Yet it also recognises, and wherever possible seeks to foster, liberty and use of property as individuals see fit.

The concept of individual rights has been gaining ground since the Enlightenment and now serves as a foundation for a variety of national constitutions and international declarations, including the US Constitution and the Universal Declaration of Human Rights. The specific embodiments of these rights have changed and broadened over time and their continuing clarification, development, and protection remain compelling political goals.

Three subtypes of individual rights can be distinguished: the right to life, liberty, and use of private property. The first two of these rights can be considered political rights in contrast with the more restricted right of property use; however, there is an overlap and this can lead to confusion. All three aspects of individual rights are central to ETS but in different ways. It is clear that ETS interferes with an individual's physical and mental health, and thus can be construed as violating one's right to life. This interference occurs whether or not ETS is sanctioned by governmental or corporate policies. Another interference caused by those who smoke is that their activity (that is, creating ETS) violates the rights of others to be let alone to pursue their own interests and activities-that is, it harms their liberty. The third individual rights subtype is to use one's own property as one wishes. This may include producing, marketing, and using a commercial product, such as tobacco. Here ETS restrictions limit the individual rights of property, but also do so, at least in part, to safeguard 
other individual rights. An additional source of difficulty lies in the abstraction of what is known as a corporate entity. Corporations are sometimes construed as entities with rights, which include freedom of speech, but few would consider the rights of a corporation equal to those of a human being.

No rights are unlimited, and the polity and courts must at times give priority to some rights over others. For instance, as important as liberty is, it usually is considered secondary to the right of life. Property rights, especially those pertaining to commercial property, are by no means absolute, and for the purposes of this paper are considered subsidiary to the right to liberty. ${ }^{2}$ Although commercial activity in some form is vital to modern society, it still can exist only at society's sufferance. As such it may be and usually is regulated. Common commercial activities are regulated through positive regulatory steps and through torts; in contrast to political rights (life and liberty), property rights are generally much more narrowly construed by regulators, legislators, and the courts. It should be noted from a normative perspective that tobacco is one of the least regulated dangerous substances. The impression promoted by the tobacco industry is to the contrary.

\section{Technical and informal definitions}

Although "individual rights" are a relatively recent concept, they underpin most political and legal processes in modern societies. ${ }^{3}{ }^{4}$ Individual rights derive from the claim that human beings are entitled to certain fundamental privileges. (Accordingly, governments do not "grant" or give people rights but instead should safeguard the inherent rights of every human being.) Yet despite the centrality of the idea of individual rights, the many attempts by philosophers to give the term a universally acceptable definition have failed. Objections arise based upon axiomatic and linguistic principles that include formal philosophical outlooks such as consequentialism and relativism. ${ }^{5}$

\section{Philosophical understandings of individual rights}

A major battle is over whether the concept of individual rights is centrally concerned with enabling individuals to make choices or to protect individuals' interests. The term "rights" has been often used in the former sense (free choice) to fight against tobacco control efforts: smokers have the liberty to consume the product, manufacturers have the freedom to make tobacco products, marketers have a right to communicate to the public, and consumers have a right to access diverse and contending viewpoints. Tobacco control efforts are also attacked in the second sense (unfair impositions) because they supposedly impose an unfair burden on particular individuals (in the form of taxes, restrictions, and social opprobrium). Yet, as already described, the term is also used to justify steps to control tobacco use. These include entitlements such as safe working conditions.

Views about individual rights are often constructed on the common sense meaning of the term rather than its formal one. Therefore it may clarify matters to make explicit what the term "individual rights" means formally to philosophers, even if there are some objections to the phrasing within the philosophical community. The term can be defined as the condition under which "Person A has no obligation (to a specific person or to people in general) not to do $\mathrm{X}^{\prime \prime}$ (the double "not" is important for my argument's consistency). This phrase frames a notion of "bare liberty". ${ }^{6}$ An important reciprocal but ambiguous meaning of the term "individual right" is that if Person A has a right to do X, then Person Q has an obligation not to interfere with $A^{\prime}$ 's doing $X$ or even that Person Q must assist A doing X. ${ }^{7}$ As this line of reasoning is applied to the question of tobacco control, the term is usually interpreted as meaning "freedom from" interference in one's practices, including the practice of smoking or otherwise consuming tobacco.

Without careful examination, it might seem from this perspective that those who would wish to restrict tobacco consumption are contravening the tobacco user's rights. ${ }^{8}$ In a sense they are, of course, but as will be seen this "right" is a limited form of liberty which contravenes a more important right, namely the right to life AND liberty of the non-smoker, including those who are not in a position to protect themselves (because of either ignorance or weakness). Upon re-examination, then, it is clear that in terms of ETS, the argument makes more sense that a person has no obligation not to breathe smoke-free air.

It is, therefore, the case that smokers contravene the individual rights of those around them, especially since the tobacco smoke is disturbing the status quo ante-that is, in the classic argument, the right to be free from assault by other people's tobacco use trumps the right to consume tobacco products. ${ }^{3}$ One has a choice about consuming one's property (smoking a cigarette), but one must breathe air to survive (preserve life). This is even more the case since the argument is saying not that smoking itself is forbidden but only smoking around others.

\section{Common understandings of individual rights}

The term "individual rights" needs to be considered not just in its formal and philosophically sophisticated meanings, but also in light of how the term is used in ordinary life and political discourse. Policy debates are generally framed less by philosophical treatises than by everyday conversation and media tropes. Thus common understandings and persuasive messages affect legislative debates and the social processes of formal and informal enforcement. ${ }^{9}$

Fundamentally, a sense of individual rights draws from deeply engrained values which exert tremendous (though not universal) appeal. Increasingly, democratic nations are adopting the view that their citizens should be interfered with to the least extent possible by governmental edict. In the hierarchy of rights specified above, there is not always a clear separation between political (life and health) and economic (property, marketing and communication) dimensions. Indeed an argument (by Nobel Laureate economist Milton Friedman among others) is that economic freedoms are bound with (and may even be the wellspring of) political rights. ${ }^{10}$ Still, there is an important distinction between interference with (and loss of) one's life, on the one hand, and the pursuit of economic interests. This is true even though sometimes they are linked in practice as well as principle. ETS in public places should be clearly positioned as advantageous to the former, even if doing so comes at some expense to the latter.

In ordinary life, forms of thought about individual rights include those of property owners to decide what activities to allow on their premises and of individuals to determine their own lifestyle and behaviour patterns. They also include the right to give informed consent. ${ }^{11}$ While rights may seem clear when considered one area at a time, such as when it comes to properly informed adults deciding to undertake risks that affect only themselves, it can become confused when the exercise of rights leads to conflicts with other rights. The matter is further clouded because of tobacco industry efforts to distort the depiction of rights. What appears initially to be a rational decision on the part of an individual may turn out to be based on misinformation or manipulated information and impressions. One example is in deciding what rules should govern the consumption of tobacco after adults and children have been deceived about the nature of tobacco products and their use. ${ }^{12}$ These questions may be more clearly understood in the context of the way individual rights have 
been presented in private corporate strategy and improperly sourced public discourse. This is because views of fairness and public policy are based on values and information, which in turn are based on shared understandings. Hence, the social construction of individual rights in tobacco control will be examined next.

\section{PLACEMENT OF INDIVIDUAL RIGHTS RHETORIC IN TOBACCO CONTROL}

In this section, individual rights principles are situated in their social and political context, beginning with the tobacco industry's involvement in distorting the concept.

\section{Tobacco industry recognition of power of rights argument}

The tobacco industry has made much of the individual rights issue but in a selective fashion. It has concentrated on the "personal liberty to take action" and the "use property as owner sees fit" aspects of the individual rights equation. The precept of "freedom from governmental interference" was favoured, but the precept of "freedom from harmful actions of others" was ignored. Unmentioned were aspects such as the right to life, the right to health, and the entitlement to the status quo ante of unpolluted air. Nevertheless, the tobacco industry congratulates itself for being in the vanguard of those protecting individual rights.

Internal reports and guides for corporate spokespeople in the tobacco industry say that the individual rights approach is critical to the strategic defence of smoking. The rhetoric of individual rights plays easily into the traditional tobacco industry view that people have a right to smoke - that is, they have no obligation not to smoke. ${ }^{13}$ The tobacco industry continues to militate for public support of smokers' rights, including opposing "unfair discrimination of adult smokers". They continue to underwrite pro-smoker citizen activism programmes because, in their words, "the growing intrusion of government in the lives of adult smokers is a threat to the freedoms of all citizens" ${ }^{\prime 14}$ The tobacco industry's publicity efforts apparently have the effect of "making smokers aware of the need to protect their rights, discrediting the tobacco control movement...[and] giving smokers a rationale for their behavior". ${ }^{15}$

The epithet "Health Nazi" was invented by the tobacco industry to discredit efforts to encourage public health. Reprehensible as the term is, it serves its purpose; it readily allows the portrayal of those concerned about health to be seen not as well intentioned humanitarians, but just the opposite: rights and life destroying monsters. Tobacco industry lobbyist Victor Crawford said that his goal in creating the term was to neutralise tobacco control advocates: "I attacked the messenger on the grounds that they were trying to destroy civil liberties...that what they were trying to do was to put their values upon the general public, and try to impose it upon the working man....and destroy his freedom of choice." 16 The term has become widely adopted, and has spillover effects that harm efforts at healthcare enhancement in other areas, such as vaccination and screening programmes.

\section{Tobacco industry biased representation of individual rights concept}

It is reasonable to argue that fully informed adults who take responsibility for the consequences of their actions should be able to use tobacco. However, it is not clear what "properly informed" means against an historical background of the tobacco industry's manipulation of individual rights, especially in terms of how ETS affects non-smokers. One could say that if the use of tobacco products harmed no one but the user, and the tobacco industry had not engaged in disinformation/manipulation campaigns, this position might have merit: people should not be denied the privilege of doing what they want if it harms no one and nothing besides themselves. But this is not the case with smoking and ETS. Non-smokers' rights to be free of harmful interference trumps the right of others to be at liberty to smoke. However, this principle is sometimes obscured because of the tobacco industry's historical ${ }^{17}$ and contemporary ${ }^{18}$ activities that have in effect created an artificially inflated belief in the rights of smokers. These activities include extensive tobacco industry instigated and funded programmes (often surreptitious) to engender beliefs about (1) the rights of smokers, (2) the rights of companies to market their products, (3) the nature of their products, and (4) the motives of governmental and tobacco control groups, without considering other individual rights.

Examples are manifold. Tobacco companies placed ads in newspapers attributing smoking restrictions to power hungry bureaucrats who would target other freedoms next. So-called "accommodation" or "courtesy" programmes (which ignored the hazards of ETS and asked the public to tolerate ETS) were promoted in deceptive ways, including the use of phoney front groups. ${ }^{19}$ Hidden payments were made to scientists ${ }^{20}$ and philosophers ${ }^{21}$ to act as third parties to propagate the tobacco industry's view concerning rights. In at least one instance, a tobacco industry trade group was even asked secretly by a philosopher for clearance to publish an article he had been paid by them to prepare. Significantly, the publication that received the manuscript (Philosophy \& Public Affairs) was a peer reviewed academic philosophy journal, and no notice had been given to them concerning the article's sponsorship. $^{22}$

In 1990, a Philip Morris vice president described to a marketing conference how his company created secret "third parties or coalitions to support marketing freedoms". He cited a Danish group Philip Morris had established called the Committee for Freedom of Commercial Expression. For the group, Philip Morris was "able to recruit more than 50 prominent Danes, including a leading Constitutional lawyer, the President of a major brewery, a leading Danish writer and philosopher and a well-known architect. The group has lobbied, conducted media briefings, participated in debates, and written articles... The coalition was probably the single greatest factor in securing Denmark's neutrality on the Directive at the Council role in May [on EU tobacco ad restrictions] ... The coalition and its ideas have attracted substantial and positive media coverage and editorial support" [emphasis added]. ${ }^{23}$ The concern is not that such groups were created, but rather that the tobacco company involved did so secretly and went to substantial efforts to disguise the origin and motives of the group. While such actions may not necessarily be illegal, they are at least misleading if not deceptive. In fact, these sponsored activities presumably would not have been undertaken had their sponsorship information been included in the message that was being propagated.

The tobacco industry has thus created an artificial world in which people's ordinary construction of relationships and meanings is distorted, making it difficult for people to make rational, informed decisions about tobacco and health. ${ }^{24}$

\section{Coercion to be avoided if possible}

At the same time, a critique that needs to be taken seriously is that tobacco control efforts do impede personal freedom and that, ultimately, they require invoking the state's coercive power to compel behaviour. Denying people the freedom to do as they wish, even if they may be physically or psychologically addicted, or if their actions are deleterious to 
their own health, is not a step to be undertaken lightly. Even some who see grave risks in smoking find it hard to justify such steps, likening them to paternalism..$^{25}$ Yet, some who denounce paternalism find that regulatory steps may nonetheless be necessary to protect those who might be harmed by the exercise of one's liberty. Consequently, they are moved to recommend governmental "guided action" to protect teens and those who are not sufficiently rational to evaluate risk. ${ }^{26}$ Still, many pro-liberty advocates, such as Stanford University law professor Robert Rabin, assert that if regulatory action by governments is premised on harm caused by smokers to others, rather than to themselves, it is in no sense paternalistic. ${ }^{27}$ In addition, when one bases the rationale on protecting children, the impetus for regulatory action is stronger still. Even ardent Libertarians take the perspective that children should be protected from tobacco smoke through government regulation. Doing so would protect the liberties of those who are not yet mature. ${ }^{28}$

Failing to stop tobacco use in public places is a violation of the rights of non-smokers, as may be seen by the definition of rights referring to the obligation to act to help others have their rights. Hence tobacco control is a justified way to protect the individual rights of the non-smoker. Indeed, the theories of Robert Nozick, an influential Libertarian philosopher, can be readily used to justify restrictions on smoking in public places. ${ }^{29}$ Likewise, writing in a Libertarian foundation publication, Kip Viscusi (a Harvard law professor who has also consulted with the tobacco industry) held that "Smoking restrictions are a sensible and appropriate policy tool for limiting exposure to cigarette smoke" ${ }^{30}$

\section{Employer responsibilities not to harm workers or public}

Another aspect of the individual rights question is the ability of employers to decide what services to offer at their own facilities, such as restaurants, and what working conditions they need to provide to employees. This is a property right since it involves contracts and so it is subsidiary to rights of life and political liberty. By definition, regulatory restrictions on smoking limit the rights of owners to do as they see fit. This is equally the case with regulations on gratuitously piping diesel fumes into working areas. Employers have a right to set the conditions for their workers, but only up to a point. Again, in light of the extensive evidence of harm, ${ }^{31}{ }^{32}$ it seems that employee exposure to ETS is a risk entirely unnecessary in the food, beverage, and entertainment industries. While markets justifiably affect wages, most would agree that some conditions are inappropriate, even if someone is willing to accept them.

\section{Prominence of non-smokers' rights in tobacco control advocacy}

At one level, some tobacco control advocates have championed the concept of individual rights. Prevention of illness-that is, improving and lengthening human lifehas been a core rationale for public health efforts. The tobacco control movement's dedication to rights is visible in the names of the leading pro-control groups, such as Canada's "Non-Smokers' Rights Association", and the USA's "Americans for Non-smokers' Rights". Some training and public awareness materials have emphasised the rights of non-smokers (especially children) to have smoke-free air. ${ }^{33}$ The right of handicapped individuals has been used as justification for extending smoke-free policies, most prominently in the Americans with Disabilities Act. Lately, too, a rallying cry has been that "all workers" should be entitled to a clean and safe working environment, which in this context means free of ETS. This justification seems relatively effective in marshalling support, especially among legislators concerned with limiting the freedom of individual action through the curbing of property rights. Finally, tobacco control advocates justifiably view themselves as being on the side of angels as they work to protect the health of smokers and their non-smoking victims. Thus, it is an easy fit with their worldview that good things, such as human rights, would also be on their side.

Yet when it comes to actually advocating individual rights, the emphasis may be lost. For instance, it seems to be quite rare that the issue of individual rights appears on websites of tobacco control organisations. In a content analysis of popular tobacco control websites, none specifically mentions or discusses rights on the first two levels of the website. By contrast, the topic of individual rights was prominently discussed in pro-tobacco websites. ${ }^{34}$ A less systematic examination of tobacco control advocacy literature also supports the view that discussions of individual rights is generally lacking.

Interestingly, content analysis of newspaper stories on efforts to limit smoking shows a distinct trend, namely those who support tobacco use are the ones who are preponderantly quoted concerning individual rights. ${ }^{35}$ This does not necessarily mean that proponents of tobacco control do not mention individual rights when interviewed; it may be that they do, but are not quoted by the journalists. Perhaps the journalists do not see such quotes as fitting the story's point. That is, they look for what they consider a balanced unfolding to a story. Because of pre-conceived notions, partly nurtured by the tobacco industry, they might tend to put "rights" discussion on the "pro" side of tobacco. Yet if either or both of these reasons accounted for the situation, it would argue for a greater emphasis to be placed on individual rights in tobacco control public statements.

\section{ADVANTAGES AND LIABILITIES OF AN EMPHASIS ON RIGHTS}

There are strategic reasons for heightening the visibility of individual rights in tobacco control, which can lead to specific tactical advantages. One is to counter the public perception that fails to see tobacco control advocates as favouring individual rights. The tobacco industry uses a discourse rich in individual rights to attract proponents; however, as noted immediately above, there appears to be relatively less usage of the term in tobacco control advocacy positioning and strategy as reflected in public discourse. This seems to remain the case despite the efforts of groups such as the one led by New York activist Joe Cherner (called BREATHE). Hence, to an outsider, tobacco control advocates may be perceived as being anti-individual rights. This impression is reflected in surveys of college students and analysis of newspaper commentaries. ${ }^{36}$ A second reason is that by promoting rights, tobacco control advocates would take advantage of the tobacco industry's opinion research and public relations expertise. Given how savvy the tobacco industry is, goes the rationale, tobacco control advocates would be well advised to counter directly whatever the industry views as being to its own advantage. ${ }^{37}$

A third strategic reason is that formulating policy based on individual rights appeals to the highest ethical standards. It places personal autonomy, and freedom from harmful situations imposed by others, above concerns such as commercial rights to communicate and disposition of personal property. Moreover, it does so without de-legitimating other worthwhile rights such as those involving property and communication. Having a strong ethical stance will help the position of tobacco control endure as both public values and behaviour change. 


\section{Tactical advantages}

Creates an action forcing mechanism while sending a clear message

A tactical advantage of emphasising individual rights in tobacco control policy is that it contains by its nature an action message. By making a declaration that ETS is an individual rights violation, the need for corrective action becomes clear. The rights emphasis also provides an intellectually unifying rhetorical device for tobacco control advocates, which can then be useful for effective communications. For example, a Lancet editorial recently formulated the issue succinctly when it called for a universal ban on smoking in public places: "All have a right to freedom from tobacco smoke and pollution." ${ }^{\prime 38}$ Although in the argument itself UK advocates emphasised the utilitarian benefits of the policy initiative (namely cost savings to the public treasury), it appeared that it was the rights component that was prominently featured in newspaper and broadcast media coverage that may have caught the public's attention.

\section{Could help recruit allies}

Individual rights arguments resonate with many lawmakers. ${ }^{39}$ Many legislators seem to oppose tobacco control legislation because it seems to violate individual rights or property rights. However, these ideology based concerns of legislators could potentially be turned to tobacco control advocates' advantage if legislators saw ETS limiting actions as conducive to individual rights. Indeed, as noted above, ETS controls can be important to the exercise of both health/life and property rights.

The message about protecting and advancing rights of health, life, and liberty should be communicated clearly. Doing so could win allies among thoughtful people of good will. Such people are more likely to become supporters of tobacco control if their fears over individual rights were assuaged.

\section{Provides action guide for advocates and passive victims}

The ordinary social interaction between smokers and nonsmokers could be affected by better guidance concerning rights, redounding to the benefit of public health. This is because non-smokers sometime refrain from speaking up when bothered by ETS because of concerns about the rights of smokers. ${ }^{40}{ }^{41}$ If the rights supportive nature of smoke-free air were stressed, victims of ETS might be encouraged to speak up. Hence there might not only be more vigorous in situ monitors, but through example a virtuous circle of public behaviour may be initiated.

Some tobacco control advocates may also experience confusion over the individual rights aspect of ETS. To the extent this is a movement-wide problem, addressing their concerns by re-framing and emphasising individual rights might bolster their effectiveness, or at least ease their concerns.

\section{Erodes usefulness of argument to tobacco industry} Another advantage is that a non-smokers' rights position denies the tobacco industry a prized psychological weapon: the "individual rights of smokers" argument. It allows the public and advocates to contest the terrain that previously has been held by the tobacco industry. It may even reclaim the victimhood status of the non-smoker, which at least, according to newspaper tropes, is now possessed by smokers.

\section{Dampens criticism of tobacco control advocates as} elitist

A tactic of the pro-tobacco side has been to make tobacco control advocates appear in the public's mind as elitists (and even racists) who use "social engineering" to impose their values on the vast middle and lower classes. ${ }^{42}$ To the extent the pro-tobacco side succeeds, control advocates are marginalised. However, assuming that the hierarchy of rights proposed by the public health community is generally acceptable (which of course is not necessarily the case) some concerned about individual rights will be persuaded by this view. Too, the arguments presented herein (that smokers are disturbing the status quo ante and therefore should defer to the non-smoker in public places) may convince some of those who see the issue in classic liberal terms as espoused by John Stuart Mill. Finally, by stressing an individual rights position, tobacco control advocates would be able to demonstrate to certain rights sensitive audiences that they wish to empower various groups to defend themselves against corporate greed and manipulation.

Another line of attack by philosopher Roger Scruton and others has been that tobacco control advocates are latterday Puritans trying to create an austere "Nanny State". ${ }^{21}$ Yet a roughly analogical case-public urination-is illuminating. People are allowed to urinate, just not in public. This restriction, enabled as it was through public sanitation engineering, does not generate much soul searching about loss of rights or liberty. It may be that heightened advocacy of individual rights of non-smokers could similarly reduce the cultural protections ETS currently enjoys.

\section{Liabilities \\ Mobilises opposition}

Despite its many advantages, reframing individual rights in a non-smokers' perspective has some potential drawbacks. For one, it can be misunderstood. The tobacco industry's publications and other efforts on behalf of smokers' rights have seemingly had the effect of making the public predisposed to respond to the topic of individual rights in a generalised way. That is, they have reserved in the public's mind the topic of rights, so when the word "rights" is mentioned, people often think of the term as meaning "the rights of smokers". To bring up the topic of rights may mobilise opposition by reminding the uncommitted about smoking restrictions. Stirring up the rights issue may be fomenting opposition to improvements in tobacco control policy. Moreover, as noted by Cohen et al ${ }^{1}$ among others, it also seems to have the effect of generating the sympathy of non-smokers for the smoker's plight.

However, for many topics of values and morals, public opinion can shift rapidly, and tobacco control and individual rights may likely become one of them. If this happened, the liability of mobilising opposition would well be neutralised.

\section{Slippery slope/foreclosure}

Some people fear that success on the ETS front will create a metaphorical slippery slope leading to new attacks on other behaviours. These people fear is that after ETS is reduced, new proscriptions would be levied against their favoured products or pastimes. Hence they become fellow travellers of tobacco interests. They oppose ETS reductions not because of beliefs about tobacco smoke but rather to protect another area. For these people, the pro-tobacco individual rights argument provides a handy defence for their latent concerns. Therefore, emphasis on individual rights might stimulate resistance to ETS elimination as a proxy. As a possible response, tobacco control advocates could show that ETS, unlike most other areas, directly harms the health of others. A core theme is that ETS occupies a special category. To the extent this distinction is emphasised in tobacco control communications, the slippery slope problem could be contained.

Still, if the argument is not drawn properly, its use could make it more difficult to pursue public health programmes in 
other areas. Automobile pollution and alcohol use are areas that invite comparison to tobacco control. Individual rights arguments therefore need to be constructed carefully if they are not to foreclose options in other health areas.

\section{RECOMMENDATIONS}

If the foregoing argument is persuasive, it is worthwhile to consider ideas for next steps.

\section{Data needed}

A first recommendation is to generate data that could reflect on the validity of the assertions that an individual rights perspective would be efficacious in advancing tobacco control. While some data were offered in the paper, additional empirical results would be helpful to determine just how tactically important an individual rights posture would be in reducing ETS. Data could also be used to fine tune approaches to address the concerns raised above.

\section{Make individual rights and freedom a cornerstone of ETS policy}

On the other hand, even if the "rights" perspective were not empirically validated as an effective way to deliver progress in tobacco control, it may be worthwhile adopting nonetheless. Principles are important. This is true even if they are not necessarily being helpful in winning support among stakeholders. An individual rights perspective could be seen as the morally correct posture independent of any short term tactical advantage. This is true even though in an age of relativism some are uncomfortable with the idea of calling something morally correct. While such hesitance is understandable given errors of earlier judgments (for example, moral justifications of slavery), it is also the case that some past unpopular and inexpedient positions were taken despite grave personal and policy costs. Today one can admire the moral fortitude of those who were able to reason out correct positions (for example, those who opposed slavery on moral grounds) and all benefit from their courageous efforts.

So even if it were not expedient to make individual rights a foundation of tobacco control today, it may in the future serve the movement well. For example, in the future public moral reasoning might better comprehend the history of tobacco industry manipulation, the addictive nature of nicotine, and the distorted political processes that protect tobacco. In that case, an individual rights posture may serve the movement well. Moreover, the position in tobacco control might be a useful precedent in other areas that are increasingly controversial, such as immunisation policy.

\section{Formulate the vision clearly}

Individual rights should be made a cornerstone for tobacco control related to ETS, with the goal of assuring that, in the words of the Lancet, "All have a right to freedom from tobacco smoke and pollution". In practice, this means working towards smoke-free public places and places of "mixed" accommodation (such as homes where children are present). The aim should be to protect the individual rights of people by not allowing smoking in public.

Lines should be clearly drawn for the policy. It should include not only indoors, such as workplaces, but places of public accommodation, such as sidewalks and public parks. Beaches and entryways should be smoke-free. When it comes to private homes and apartments, smoking should be allowed only as long as it does not affect neighbours. Future research should study the competing rights involved in restricting smoking in the presence of children, including by pregnant women.

In essence, the Lancet position should be the cornerstone of ETS policy. Yet even while this policy is being put into practice, its overall aim should remain to ensure that tobacco control stands for the advancement, not suppression, of individual rights. It should stand for this goal not only in principle and practice, but in the popular imagination as well.

Part of achieving this objective may be to emphasise the idea that there is a hierarchy of individual rights, with protection of life and health as the first among several, sometimes clashing, forms of individual rights. Commonly this hierarchy is ignored when arguments focus on only one right, especially when that rights concerns property and governmental control. The distinction among these varying individual rights often escapes the public (and many experts), so it would be beneficial for healthcare professionals and the public to clarify frequently the hierarchy.

\section{Communicate the view widely}

To have influence as a stance and operational guide, the individual rights view needs to be clearly enshrined within tobacco control advocacy regarding ETS. As part of tobacco control's capacious enterprise, there are many messages and message formats for many different audiences. Despite this situation, it would be useful for leaders to make periodic efforts to remind their audiences that the central message of tobacco control is to help people to have a full life in which their rights as individuals can be realised. In effect, individual rights would become a framing trope for public and training pronouncements. Whenever a reasonable opportunity presents itself to allude to the individual rights foundation of tobacco control, it should be utilised. At the very least, this should especially include low cost measures, such as the websites of tobacco control organisations. Vigorous debates are also carried out on the internet and on the pages of newspapers. Consideration should be given to having a systematic way to monitor and respond to high visibility opportunities to put across the individual rights viewpoint of the tobacco control movement. Particularly useful might also be to have meetings on this issue with legislators and newspaper editorial boards, again honing in on the individual rights aspects of tobacco control. Tobacco control advocates should protest newspaper reports that paint smokers as victims or portray advocates as against rights with the same vociferousness that is applied to unfair demographic or cultural stereotypes. Such steps may make the individual rights perspective the intellectual property of tobacco control advocates rather than pro-tobacco forces, as now appears to be the case.

\section{Determine best ways to communicate "individual} rights" messages to key stakeholders and audiences Assuming that research shows the individual rights messages to be tactically effective, it would be helpful to get insight into how to best frame and deliver the message to internal and external audiences. Research could be devoted to this topic, especially in terms of the views and receptivity of professionals and volunteers in tobacco control advocacy. Opinion research and surveys might be extremely useful for identifying the extent to which concern over individual rights is affecting the tobacco control movement. Such research could help identify the value of additional training on this issue and what forms of messages might be best for audiences internal to the tobacco control movement.

\section{CONCLUSION}

This paper has analysed formal and conventional meanings of individual rights and their bearing on tobacco control policy related to ETS. Based on this analysis, there is logic in asking tobacco control advocates to give more emphasis to the individual rights protections afforded by policies that restrict ETS. As a general posture, policy should be designed to be responsive to individual rights of both smokers and non-smokers, with right to life/health (that is, rights of 


\section{What this paper adds}

This paper argues that individual rights should be embraced as an ethical cornerstone of public health policy regarding tobacco control, most especially in the area of ETS. There have been efforts to emphasise individual rights in tobacco control (efforts which are continuing), but much more could be done. Making rights central to tobacco control is not without problems, but there are potential benefits. The most important of them, though, is that several structural and moral problems that have worked against progress in tobacco control might be overcome.

non-smokers) having priority. Policy could be framed so that smoking would not be permitted in co-occupied places, such as offices, sidewalks, and parks, but that appropriately informed adults would, with some restrictions, still be entitled to smoke in private. A policy along these lines could serve the cause of tobacco control advocacy by reinforcing further the community's dedication to the concept of individual rights. Especially commended to advocates is the use of the hierarchy described above (which places life and health above liberty to use property). It would also serve to focus public attention on the status quo ante violations perpetrated by tobacco companies against non-smoker rights to health and liberty.

Making a pro individual rights policy the hallmark of tobacco control policy is not cost-free and entails risks. Yet on balance much may be gained by giving individual rights a still more prominent place in tobacco control advocacy. Indeed, much recent progress in limiting public exposure to ETS may be attributable to tobacco control advocates giving greater stress to individual rights arguments. Still greater emphasis on individual rights of non-smokers should help maintain or even accelerate progress towards smoke-free air in all public and shared private places.

\section{ACKNOWLEDGEMENTS}

The research and analysis reported herein was supported by a grant from the Robert Wood Johnson Foundation. The author benefited from the advice of Regina Carlson, Brion Fox, Stanton Glantz, Anne Landman, Michelle Larkin, Joe Marx, Dennis Whitcomb, Amy Williamson, and three anonymous reviewers.

Competing interests: none declared

\section{REFERENCES}

1 Jacobson PD, Wasserman J, Anderson JR. Historical overview of tobacco legislation and regulation. J Soc Issues 1997;53:75-95.

2 Goodin RJ. No smoking: the ethical issues. Chicago: University of Chicago, 1984.

3 Herbert G. Philosophical history of rights. New Brunswick, New Jersey: Transaction, 2002.

4 Wellman C. Rights and duties. New York: Routledge, 2002.

5 Scheffler S. Consequentialism and its critics. New York: Oxford University Press, 1984.

6 Weinberg J. Social philosophy. Englewood Cliffs, NJ: Prentice-Hall, 1979

7 Waldron J. Introduction. Theories of rights. Oxford: Oxford University Press, 1984.

8 Rabin R, Sugarman S, eds. Regulating tobacco. New York: Oxford University Press, 2001.

9 Stone D. Policy paradox: the art of political decision making, revise ed. New York: Norton, 2001.

10 Friedman M. Capitalism and freedom. Chicago: University of Chicago Press, 1962.

11 Kozlowski L, Edwards BQ. "Not safe" is not enough: smokers have a right to know more than there is no safe tobacco product. Tobacco Control 2005; 14(suppl II):ii3-7.

12 Glantz SA, Slade J, Bero LA, et al. eds. The cigarette papers. Berkeley: University of California Press, 1996:391-435.
13 Philip Morris. Industry Summary (1992, est.) Bates No. 20513634252051363618. http://tobaccodocuments.org/landman/20513634253618.html (Accessed 10 Dec 2003).

14 Brown \& Williamson. My voice counts: Introduction. http:// www.brownandwilliamson.com/index_sub2.cfm?Page = /GC/ Index.cfm\%3FID\%3D44\%26Sect\%3D4 (Accessed 30 Dec 2003).

15 Cardador M, Hazan A, Glantz S. Tobacco industry smokers' rights publications: a content analysis. Am J Public Health 1995;85:1212-17, 1215.

16 Borio G. Victor Crawford on 60 minutes. Tobacco.org, Tobacco News 4/5/ 95. http://www.tobacco.org/News/95.04.05_Tob_News.html\#aanazis (Accessed 19 Dec 2003).

17 Kluger R. Ashes to ashes: America's hundred-year cigarette war, the public health, and the unabashed triumph of Philip Morris. New York: Vintage, 1997.

18 Addiction website. Supporters website links. http://www.addictionresourcelist.com/Top_Health_Addictions_Substance_Abuse Tobacco_Industry_Supportershtml. (Accessed 4 Jan 2004).

19 Glantz S. Tobacco scam website. www.tobaccoscam. ucsf.edu (Accessed 4 Jan 2004).

20 Chapman S. "We are anxious to remain anonymous": the use of third party scientific and medical consultants by the Australian tobacco industry, 1969 to 1979. Tobacco Control 2003;12(suppl III):iii31-7.

21 Bates C. Roger Scruton high priest philosopher of the libertarian right defrocked and exposed as 'grimy hack' for tobacco industry. Press release 25 March 2002, ASH UK, http://www.ash.org.uk/html/press/020124.html (Accessed 4 Jan 2004).

22 LePere J. J C Luik's paper for publication. 9 November 1996, Confederation of European Community Cigarette Manufacturers, Ltd, http:// www.pmdocs.com/getimg.asp?pgno $=0$ \&start $=0$ \&if $=$ avpid $\&$ \&ool $=2025498204 \&$ docid $=2025498204 /$ $8205 \&$ docnum $=1$ \&summary $=0$ \&sel 1 (Accessed 2 Jan 2005)

23 Dollison J. PMI marketing conference -9000 'corporate affairs' Philip Morris 21 June 1990, Bates No. 2500120138/0153. http:// tobaccodocuments.org/landman/2500120138-0153.html. (Accessed 8 Jan 2004).

24 Tyrrell I. Deadly enemies: tobacco and its opponents in Australia. Sydney: University of New South Wales Press, 1999.

25 Rabin R, Sugarman SD, eds. Smoking policy: law, politics, and culture. New York: Oxford University Press, 1991.

26 Sunstein C, Thaler RH. Libertarian paternalism is not an oxymoron. American Enterprise Institute Working Paper 03-2, April 2003. http:// www.aei.brookings.org/admin/pdffiles/phpti.pdf (Accessed 19 Dec 2003).

27 Rabin R. Some thoughts on smoking regulation. Stanford Law Review $1991 ; 43: 475-96$

28 Taylor J. Interview with Jerry Taylor [Cato Institute] on CNN Crossfire TV Program, The U.N. : what are they thinking about war with Iraq, Broadcast 30 January 2003 - 19: 00 ET. http://www.cnn.com/TRANSCRIPTS/0301/30/ cf.00.html (Accessed 19 Dec 2003).

29 Nozick R. Anarchy, state and utopia. New York: Basic Books, 1974.

30 Viscusi WK. Secondhand smoke: facts \& fantasy. Regulation: The Cato Review of Business \& Government, 1995;18(3). http://www.cato.org/pubs/ regulation/reg18n3e.html (Accessed 26 Dec 2003).

31 Vineis P, Airoldi L, Veglia F, et al. Environmental tobacco smoke and risk of respiratory cancer and chronic obstructive pulmonary disease in former smokers and never smokers in the EPIC prospective study. BMJ 2005;330:277

32 Kawachi, I. More evidence on the risks of passive smoking. BMJ 2005:330:265-6.

33 Carlson R. NJ GASP Q\&A, Printed leaflet. Summit, NJ: NJ GASP ca, 1998

34 Rutgers Tobacco Control Research Project. Analysis of pro-tobacco control and anti-tobacco control websites to determine coverage of human rights arguments. http://www.rightsmoke.org/pdf/websites.pdf (Accessed 30 Dec 2004).

35 Rutgers Tobacco Control Research Project. Mass media coverage of tobacco control in terms of rights. http://www.rightsmoke.org/sociocultmap.htm (Accessed 30 Dec 2004).

36 Bagley Koyle S. Rights, choice and justice: a rhetorical analysis of statements opposing tobacco regulation. Paper presented at the International Communication Association annual meeting, New Orleans, 28 May, 2004

37 Chapman S. Other people's smoke: what's in a name? Tobacco Control 2003;12:113-4.

38 Hall C. Ban smoking in public, say top doctors. Electronic Telegraph (Daily Telegraph) www.telegraph.co.uk/news/main.jhtml?xml = / news/2003/11/ 26/nsmok26 xml (Filed: 26/11/2003) (Accessed 3 Jan 2005).

39 Cohen JE, Milio N, Rozier RG, et al. Political ideology and tobacco control. Tobacco Control 2000;9:263-7.

40 Poland B, Stockton L, et al. Interactions between smokers and non-smokers in public places: a qualitative study. Can J Public Health 1999;90:330-3.

41 Poland B. The 'considerate' smoker in public space: the micro-politics and political economy of 'doing the right thing'. Health \& Place 2000;6:1-14.

42 Berger PL. Environmental tobacco smoke: ideological issue and cultural issue. In Tollison RD, eds. Clearing the air: perspectives on environmental tobacco smoke. Lexington, Massachusetts: Heath, 1988:85-8. 